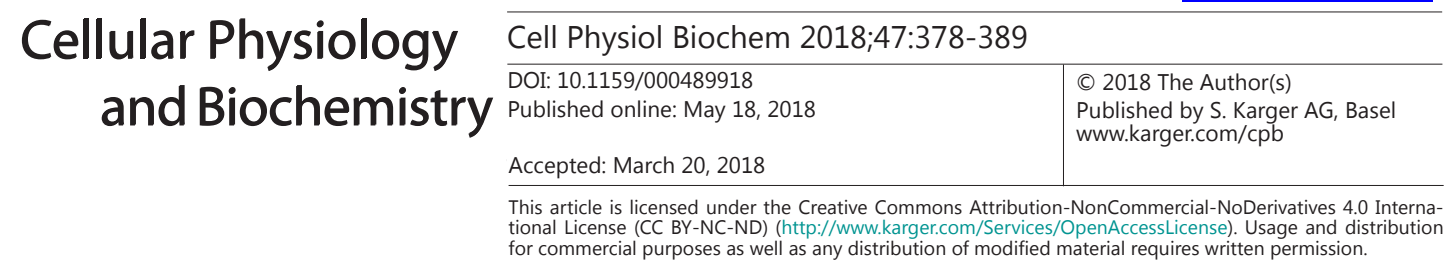

\title{
Proteomics Analysis of Testis of Rats Fed a High-Fat Diet
}

\author{
Xiu-Yan Yang ${ }^{a} \quad$ Yu-jie Gu ${ }^{a}$ Tian An ${ }^{a} \quad$ Jia-Xian Liu ${ }^{c}$ Yan-Yun Pan ${ }^{a}$ \\ Fang-Fang $\mathrm{Mo}^{\mathrm{b}}$ Jia-Nan Miao ${ }^{\mathrm{a}}$ Dan-Dan Zhao ${ }^{\mathrm{b}} \quad$ Dong-Wei Zhang $^{\mathrm{b}}$ \\ Si-Hua Gao ${ }^{b}$ Guang-Jian Jiang ${ }^{b}$
}

aSchool of Chinese Medicine, Beijing University of Chinese Medicine, 'biabetes research Center, Beijing University of Chinese Medicine, Beijing, China cLeonard Davis School of Gerontology, University of Southern California, Los Angeles, CA, USA

\author{
Key Words \\ High-fat diet $\cdot$ Testis $\bullet$ Proteome $\bullet$ Long non-coding RNAs
}

\begin{abstract}
Background/Aims: The adverse effects of obesity on male fertility have been widely reported. In recent years, the relationship between the differential expression of proteins and long noncoding RNAs with male reproductive disease has been reported. However, the exact mechanism in underlying obesity-induced decreased male fertility remains unclear. Methods: We used isobaric tags for relative and absolute quantification to identify differential protein expression patterns in the testis of rats fed a high-fat diet and normal diet. A microarray-based gene expression analysis protocol was used to compare the differences in long non-coding RNAs in high-fat diet-fed and normal diet-fed rats. Five obviously upregulated or downregulated proteins were examined using western blot to verify the accuracy of their expression. Then, we carried out functional enrichment analysis of the differentially expressed proteins using gene ontology and pathway analysis. Finally, the metabolic Gene Ontology terms and pathways involved in the differential metabolites were analyzed using the MetaboAnalyst 2.0 software to explore the co-expression relationship between long non-coding RNAs and proteins. Results: We found 107 proteins and 263 long non-coding RNAs differentially expressed between rats fed a high-fat diet and normal diet. The Gene Ontology term enrichment analysis showed that the protein function most highly enriched was related to negative regulation of reproductive processes. We also found five Gene Ontology terms and two metabolic pathways upregulated or downregulated for both proteins and long non-coding RNAs. Conclusion: The study revealed different expression levels for both proteins and long non-coding RNAs and showed that the function and metabolic pathways of differently expressed proteins were related to reproductive processes. The Gene Ontology terms and metabolic pathways upregulated or downregulated in both proteins and long non-coding RNAs may provide new candidates to explore the mechanisms of obesity-induced male infertility for both protein and epigenetic pathways.




\section{Cellular Physiology Cell Physiol Biochem 2018;47:378-389 \begin{tabular}{l|l} 
and Biochemistry Published online:May 18, 2018 & $\begin{array}{l}\text { C } 2018 \text { The Author(s). Published by S. Karger AG, Basel } \\
\text { www.karger.com/cpb }\end{array}$ \\
\hline
\end{tabular} Jiang et al.: Effects of Obesity on Male Fertility}

\section{Introduction}

Obesity leads to various health problems such as insulin resistance, dyslipidemia, hypertension, and chronic inflammation, all of which contribute to high rates of mortality and morbidity [1]. Many of these complications are associated with an additional impact on male reproduction. Many factors are clearly associated with decreased male reproductive capacity, including environmental effects, metabolic dysfunction, and genetic polymorphisms [2-3]. In this study, we focused on the effects of obesity on male infertility.

As a result of improved living standards and dietary variation, the prevalence of obesity continues to increase [4]. Previous studies suggest that the body mass index (BMI) of obese males and semen quality determine the relationship between metabolic disorders and hormonal imbalance. Obesity reduces sperm quality and alters fertility by affecting spermatogenesis function $[5,6]$.

Male rats were used to simulate the habits of obese patients to study the molecular mechanism of altered protein expression in the testes of rats with high-fat diet-induced obesity (DIO). We used iTRAQ to investigate the differentially expressed proteins in the testis. Unlike previous studies on single proteins and genes, proteomics studies the disease mechanism from a holistic, multi-faceted, dynamic perspective $[7,8]$. We have not only tested the protein expression in the testis tissue, but also conducted gene ontology (GO) analysis and gene and genomic (KEGG) biological pathway analysis to predict the differential expression of long non-coding RNAs (lncRNAs). If differentially expressed proteins and lncRNAs alter the same pathway, it may be important in the fertility reduction of obese men. LncRNA is a non-coding RNA that is longer than $200 \mathrm{nt}$ [9]. In a recent study that explored the relationship between lncRNA and obesity, lncRNA and mRNA interactions revealed potential genes that might play important roles in the pathogenesis of obesity-related low fertility [10]. Although several lncRNAs are critical in disease development, most lncRNA functions remain unclear [11]. We examined rat testes to explore the molecular mechanisms behind the reproductive changes resulting from a high-fat diet, to reduce the adverse effects of obesity on male reproduction.

\section{Materials and Methods}

\section{Animal experiments}

Sprague-Dawley (SD) male rats (aged 6 weeks: Hua Fu Kang Company, Beijing, China) were housed in plastic cages and fed a normal diet in controlled conditions: room temperature of $23 \pm 2{ }^{\circ} \mathrm{C}$, relative humidity of $45 \pm 10 \%$, and a $12 \mathrm{~h}$ light-dark cycle. After adaptation for 1 week, the rats were randomly distributed into two groups: high-fat diet and normal. Each group contained 7 rats. The rats in the normal group were fed a standard diet and the rats in the high-fat diet group were fed a high-fat diet (20\% sucrose, 10\% lard, $2.5 \%$ cholesterol, $0.2 \%$ sodium cholic, and $67.3 \%(\mathrm{w} / \mathrm{w}$ ) standard chow). The two groups of animals were fed for 12 weeks (until the average body weight of high-fat diet group was $>120 \%$ normal). This study was approved by the Beijing University of Chinese Medicine's Animal Ethics Committee. All animal manipulations were undertaken according to the guidelines of the Animal Care Committee and all experiments were carried out in accordance with the approved guidelines.

\section{Semen quality analysis and testis hematoxylin-eosin staining}

At the end of the $12^{\text {th }}$ experimental week, the rats were killed by cervical dislocation. The deferens and epididymis were separated and spermatozoa were obtained by emptying the deferens and puncturing the epididymis in preheated human tubal cultures. Then spermatozoa were centrifuged $\left(1500 \times \mathrm{g}, 4^{\circ} \mathrm{C}, 8 \mathrm{~min}\right)$ to collect the supernatant fluid. Semen was obtained from the epididymis tail and transferred to Ham's F10 medium (Bioway Biotechnology Co., Ltd., Beijing, China) for analysis of sperm density and motility using the computer-assisted semen analyzer (CASA) (TOX IVOS, Hamilton Thorne, Beverly, MA, USA). The testicle samples collected from the rats were paraffin-embedded, sectioned (thickness, $4 \mu \mathrm{m}$ ), and stained with hematoxylin-eosin (HE) for evaluation by light microscopy (Olympus, Tokyo, Japan). 


\section{Cellular Physiology Cell Physiol Biochem 2018;47:378-389 \begin{tabular}{l|l|l} 
and Biochemistry 10.1159/000489918 & $\begin{array}{l}\text { D } 2018 \text { The Author(s). Published by S. Karger AG, Basel } \\
\text { www.karger.com/cpb }\end{array}$
\end{tabular} Jiang et al.: Effects of Obesity on Male Fertility}

\section{Protein preparation and ITRAQ labeling}

The frozen testicle tissue in the liquid nitrogen from normal group and high-fat diet group was used for iTRAQ analysis. The tissue sample of each group was from the mixture of all the 7 rats' testicle. Each sample was diluted in a lysis buffer (7 M urea, $2 \mathrm{M}$ thiourea, $0.1 \%$ CHAPS, $40 \mathrm{mM}$ Tris-HCL, pH 8.5) containing $1 \mathrm{mM}$ phenylmethylsulfonyl fluoride (PMSF), $2 \mathrm{mM} \mathrm{EDTA}$, and $10 \mathrm{mM}$ DTT, lysed by sonication, and then centrifuged at $25,000 \times \mathrm{g}$ for $20 \mathrm{~min}$ at $4{ }^{\circ} \mathrm{C}$. The collected supernatant was stored at $-80{ }^{\circ} \mathrm{C}$ for subsequent iTRAQ and western bolt analysis. The protein concentration from each group of testicle sample was determined using the Bradford assay [12].

After the protein was quantified, $200 \mu \mathrm{g}$ protein solution was placed in a centrifuge tube, $100 \mu \mathrm{l}$ of iTRAQ kit Dissolution Buffer was added, and the solution was centrifuged at 12, $000 \mathrm{rpm}$ for $20 \mathrm{~min}$. The solution at the bottom of the tube was discarded, and trypsin was added to the tube. After centrifugation at $12,000 \mathrm{rpm}$ for $20 \mathrm{~min}$, the pellet on the bottom of the tube contained the digested peptide.

iTRAQ labeling was done according to the kit protocol (ABI, Foster City, CA, USA). First, a reduction reagent (50 mM final concentration; 8-plex iTRAQ kit, AB SCIEX, Redwood City, CA, USA) mixed with 150 $\mu \mathrm{l}$ of isopropanol was added to the protein sample (the collected supernatant) and incubated at ambient temperature for $2 \mathrm{~h}$. After rinsing a $10 \mathrm{kD}$ ultrafiltration cartridge with $70 \%$ ethanol and deionized water, the protein solution was added and centrifuged at 13, $400 \times \mathrm{g}$ for $20 \mathrm{~min}$. To detect the labeling efficiency and quantitative accuracy, the protein samples $(7 \mu \mathrm{l}$ rats in the high-fat diet and normal groups, $(1 \mu \mathrm{l}$ of testis per rat) were mixed $(1 \mu \mathrm{l}$ per sample) and desalted using a Ziptip $(2 \mu \mathrm{l}$ C18 ZTC18M096, Millipore, Bedford, MA, USA) to perform MALDI-TOF-TOF (AB SCIEX 4800 Plus) for verification that the labeling reaction was complete. The reaction was terminated with deionized water and the protein samples were thoroughly mixed. After centrifugation, the dried protein sample was stored at $-80^{\circ} \mathrm{C}$ until use. The tryptic peptides in the two protein samples from the normal and high-fat diet group were labeled with iTRAQ reagents (isobaric tags 113 and 114 for the normal and 117 and 119 for the high-fat diet group).

\section{HPLC}

For LC-MS/MS analysis, the peptide mixture was loaded onto a reverse-phase trap column(Thermo Scientific EASY-nLC1000 System)connected to the C18 reversed-phase analytical column (Thermo Scientific Easy Column, 10 -cm-long, $75-\mu \mathrm{m}$ inner diameter, $3-\mu \mathrm{m}$ resin) in buffer A ( $0.1 \%$ formic acid). It was separated with a linear gradient of buffer B ( $84 \%$ acetonitrile and $0.1 \%$ formic acid) at a flow rate of $350 \mathrm{nl} / \mathrm{min}(0-$ $35 \%$ buffer B for $50 \mathrm{~min}, 35-90 \%$ buffer B for $5 \mathrm{~min}, 90 \%$ buffer B for $5 \mathrm{~min}$ ).

\section{RNA isolation}

Twelve weeks later, spermatozoa were harvested from the rats in each group. According to the manufacturer's instructions, the total RNA was isolated using TRIzol reagent (Life Technologies) and purified using the RNeasy Protect Mini Kit (QIAGEN). The total RNA from each sample was quantified using a NanoDrop ND-1000 (Thermo Fisher Scientific), and the RNA integrity was measured by standard denaturing agarose gel electrophoresis.

\section{LncRNA microarray experiment}

RNA quantity and quality were measured using the NanoDrop ND-1000. RNA integrity was assessed using standard denaturing agarose gel electrophoresis. Arraystar Mouse LncRNA Microarray V3.0 was used for detection of IncRNA and mRNA expression. Arraystar Mouse circRNA Array and Agilent miRNA microarray were used for profiling the circRNAs and miRNAs expression. All microarray analysis was performed by KangChen Bio-tech (Shanghai, China). The concentration and specific activity of the labeled circRNAs (pmol Cy3/ $\mu \mathrm{g}$ circRNA) were measured using the NanoDrop ND-1000. Each labeled circRNA (1 $\mu \mathrm{g})$ was fragmented by adding $5 \mu \mathrm{l} 10 \times$ Blocking Agent and $1 \mu \mathrm{l} 25 \times$ Fragmentation Buffer, heated at $60^{\circ} \mathrm{C}$ for $30 \mathrm{~min}$, and diluted with $25 \mu \mathrm{l} 2 \times$ GE Hybridization buffer. Hybridization solution (50 $\mu$ l) was dispensed into the gasket slide and added to the IncRNA expression microarray slide. The slides were incubated for $17 \mathrm{~h}$ at $65^{\circ} \mathrm{C}$ in an Agilent Hybridization Oven. Agilent Feature Extraction software (version 10.7.3.1) was used to analyze acquired array images. Raw signal intensities were normalized using the quantile method. Quantile normalization and subsequent data processing were performed using the GeneSpring GX v11.5.1 software package (Agilent Technologies).

\section{KARGER}




\section{Cellular Physiology Cell Physiol Biochem 2018;47:378-389

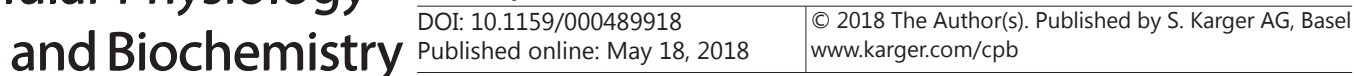 \\ Jiang et al.: Effects of Obesity on Male Fertility}

\section{Bioinformatics analysis and protein network analysis}

We conducted a gene ontology (GO) analysis (http://www.geneontology.org) to construct meaningful annotations of genes and gene products. Ontology covers areas such as biological processes, cellular components, and molecular functions. We also conducted a KEGG pathway analysis to collect clusters of molecular interactions and response networks. - $\log 10$ (p-value) represents the concentration fraction, showing the significance of the pathway and GO term enrichment.

\section{Western blotting}

The extract (the supernatant collected in section 2.3) was centrifuged at 10, $000 \mathrm{x}$ g for $15 \mathrm{~min}$ at 4 ${ }^{\circ} \mathrm{C}$, the supernatant was transferred to a clean tube and the protein samples were separated via SDS-PAGE. After electrophoresis, the resolved proteins were transferred to PVDF membrane. The membrane was then blocked for $1 \mathrm{~h}$ with TBST (50 mM Tris-HCl, pH 7.6 and $150 \mathrm{mM} \mathrm{NaCl)} \mathrm{containing} \mathrm{5 \%} \mathrm{(w/v)} \mathrm{nonfat} \mathrm{milk,}$ and incubated overnight with the primary antibodies: anti-Crisp1, anti-Epha5, anti-Mapk1, anti-Smad2 and anti-GAPDH (Proteintech, 1:10000). The membrane was washed three times with TBST and incubated with secondary antibody Peroxidase-conjugated Affinipure Goat Anti-Rabbit IgG (Proteintech, 1: 10000 ) for $1 \mathrm{~h}$. The membrane was again washed three times and subsequently developed. The bands were visualized using SuperSignal West Micro Chemiluminescent Substrate (Pierce, part of Life Technologies) and recorded on x-ray film (Fuji Medical, Tokyo, Japan). Finally, the visualization strip was quantified using the Quantity One software on the GS-800 densitometer (Bio-Rad Laboratories, Hercules, CA, USA).

\section{Quantitative data analysis}

Scaffold Q+ (version Scaffold_4.4.8, Proteome Software Inc., Portland, OR) was used to quantitate Label Based Quantitation (iTRAQ TMT, SILAC, etc.) peptide and protein identifications. Peptide identifications were accepted if they could be established at greater than $91.0 \%$ probability to achieve an FDR less than $1.0 \%$ by the Scaffold Local FDR algorithm. Protein identifications were accepted if they could be established at greater than $99.0 \%$ probability to achieve an FDR less than $1.0 \%$ and contained at least 2 identified peptides. Acquired intensities in the experiment were globally normalized across all acquisition runs. Individual quantitative samples were normalized within each acquisition run. Intensities for each peptide identification were normalized within the assigned protein. The reference channels were normalized to produce a 1:1 fold change. All normalization calculations were performed using medians to multiplicatively normalize data.

\section{MS and Mascot}

Tandem mass spectra were extracted using ProteoWizard version 3.0.8789. Charge state deconvolution and deisotoping were not performed. The SwissProt Rattus database searched was Mascot version 2.5.1(Matrix Science, London, UK; version 2.5.1).

\section{Statistical analysis}

The statistical significance of microarray data was analyzed in terms of fold change using the Student's t-test (SPSS, 13.0 ) to correct the $p$-value. $p<0.05$ was considered statistically significant.

\section{Results}

\section{Body weight and glycolipid metabolism of experimental animals}

After 12 weeks, we compared the fasting levels of blood glucose (GLU), low-density lipoprotein (LDL), high-density lipoprotein (HDL), and triglycerides (TG), as well as the body weight of DIO and normal rats. The results showed that the levels of HDL, LDL, and TG in the DIO group were not significantly higher than levels in the control group. However, the fasting blood glucose level and body weight of the DIO rats were significantly higher than in the control group (Fig. 1).

Semen analysis

CASA analysis of spermatozoa extracted from the epididymides and spermaducts revealed that both the sperm concentration and motility percentage significantly decreased 
in the DIO group compared with the control group $(p<0.05, \mathrm{n}=7)$ (Fig. 2).

\section{Testicular morphological structure}

Under light microscopy, abundant seminiferous tubules with large diameters and intact basement membranes were observed in the testicular structure of the control group, and the cell structure was clear at all stages. The mesenchyme was composed of loose connective tissue with large and round cells. Compared with the control group, obvious pathological changes were observed in the testicular tissue of the DIO group (Fig. 3). The sperm cells fell in clusters in the lumen. Many atrophic and distorted seminiferous tubules were destroyed. In each field of measurement, the number of cells was significantly reduced (Fig. 3A-3B).

\section{Differentially expressed proteins in testes of obese} rats and nor-

mal rats

In the present study, 6, 795 proteins were identified in the testicular samples. We compared the expression levels of proteins in the testes of the DIO and control groups. Results showed 107 differentially expressed proteins between the DIO and control groups. Of these proteins, 67 were downregulated and 40 were upregulated, and we

Fig. 3. (A) Morphological changes in the testes of male rats. Magnification $\times 20$, scale bar $100 \mu \mathrm{m}$; magnification $\times 40$, scale bar $50 \mu \mathrm{m}$. Testicular section from a normal rat showing clear cell structure, loose connective tissue and large spermatogenic cells. Testicular section from a DIO group rat, presented in the Fig.s as DIO (diet-induced obesity) showing atrophic and distorted seminiferous tubules and fewer spermatogenic cells. (B) Quantitative analysis of spermatogenic cells in testis. The number of seminiferous tubules containing five or more apoptotic cells was calculated using TUNEL stain. The apoptosis percentage was calculated as the ratio of apoptosis-positive seminiferous tubules to the total number of seminiferous tubules. Data $(n=7)$ are represented as mean \pm SEM. $* \mathrm{p}<0.05$.

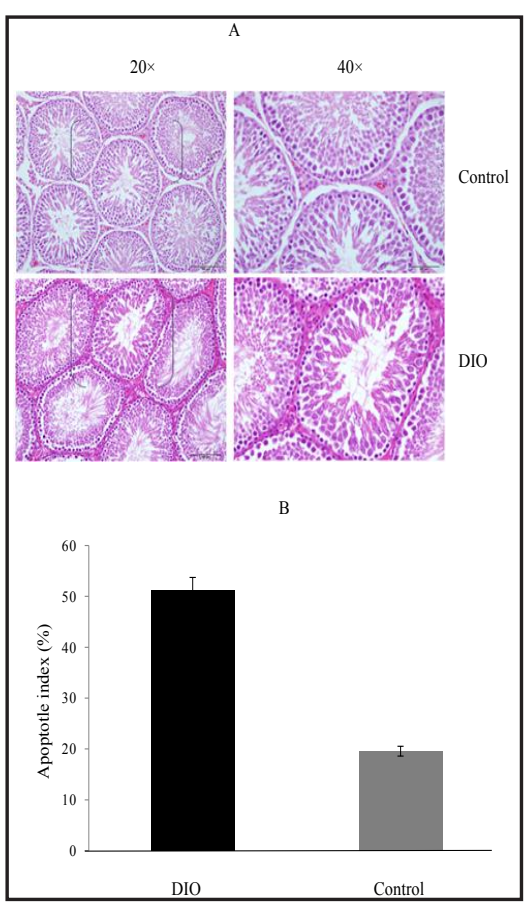


listed the top 20 up-regulated and 20 down-regulated proteins, a fold change cut-off ratio of $>1.3$ (up-regulated) or $<0.77$ (down-regulated) was selected to designate differentially expressed proteins $(p<0.05)$ for future study. (Table 1 and 2, respectively)

\section{Differentially expressed IncRNAs between and normal rats \\ We found 263 IncRNAs} differentially expressed, with fold change $\geq 2.0$ and $p<0.05$, in the samples from the high-fat diet rats compared with the normal rats. Among them, 115 IncRNAs were upregulated and 148 IncRNAs were downregulated. The top 20 upregulated and downregulated lncRNAs are listed in Table 3.

\section{Gene ontology analysis}

We used all 107 differentially expressed proteins (both upregulated and downregulated) for GO analysis in the testis samples extracted from rats. GO analysis explores proteins involved in biological process, cellular component, and molecular function. The top 10 generally changed GO terms classified by biological process, cellular component, molecular function, and ranked by fold enrichment are listed (Fig.4). The most enriched and meaningful cellular component terms were related to the extracellular region such as "extracellular vesicle," "extracellular matrix," "extracellular organelle," and "extracellular membrane-bounded organelle." The most enriched biological process terms were related to extra cellular metabolic processes such as "cellular component disassembly," "extracellular matrix organization," and "extracellular structure organization." We found the most enriched molecular function terms were related to molecule structure. Representative terms were "structural molecule activity," "extracellular matrix structural," and "growth factor binding."

\section{Pathway analysis}

Pathway enrichment analysis indicated that 50 pathways were significantly enriched $(p<0.05)$ among the differentially expressed proteins, including cytoskeleton remodeling,
Table 1. Differentially expressed proteins in mouse testis between DIO and control groups (up-regulated)

\begin{tabular}{lccc}
\hline Accession Number & Full Name & Gene Symbol & Ratio(D/N) \\
\hline NQO2_RAT & Ribosyldihydronicotinamide dehydrogenasequinone & Nqo2 & 2.25 \\
EPHA5_RAT & Ephrin type-A receptor 5 & Epha5 & 2.17 \\
A0A0G2JSR8_RAT & Cytochrome P450, family 17, subfamily a, polypeptide 1 & Cyp17a1 & 1.91 \\
B2RYK7_RAT & LOC502201 protein & Lrrc29 & 1.69 \\
SMAD2_RAT & Mothers against decapentaplegic homolog 2 & Smad2 & 1.59 \\
A0A0H2UHF6_RAT & PRA1 family protein 3 & Arl6ip5 & 1.58 \\
D4A644_RAT & Protein Map7d1 & Map7d1 & 1.53 \\
D3ZHR8_RAT & Protein Tyw3 & Tyw3 & 1.53 \\
CARM1_RAT & Histone-arginine methyltransferase CARM1 & Carm1 & 1.52 \\
D4A6W6_RAT & Protein RGD1561333 & RGD1561333 & 1.48 \\
D3ZJM7_RAT & Protein Mcph1 & Mcph1 & 1.48 \\
ATP5E_RAT & ATP synthase subunit epsilon, mitochondrial & Atp5e & 1.47 \\
A0A0G2K523_RAT & Protein O-mannosyl-transferase 1 & Pomt1 & 1.46 \\
EGLN1_RAT & Egl nine homolog 1 & & 1.45 \\
RS9_RAT & 40S ribosomal protein S9 & Rps9 & 1.44 \\
A0A0G2JWB6_RAT & Protein Pxdn & Pxdn & 1.42 \\
A0A0G2K743_RAT & Uncharacterized protein & & 1.42 \\
G3V950_RAT & LYR motif-containing protein 1 & Lyrm1 & 1.42 \\
D4A727_RAT & Protein Magea8 & Magea8 & 1.42 \\
ISK2_RAT & Serine protease inhibitor Kazal-type 2 & Spink2 & 1.39 \\
\hline
\end{tabular}

Table 2. Differentially expressed proteins in mouse testis between the DIO and control groups (down-regulated)

\begin{tabular}{lccc}
\hline Accession Number & Full Name & Gene Symbol & Ratio(D/N) \\
\hline CAH3_RAT & Carbonic anhydrase & Ca3 & 0.50 \\
A0A0G2JTX7_RAT & Protein Col6a5 & Col6a5 & 0.51 \\
A0A0G2JWX4_RAT & Keratin, type II cytoskeletal2 epidermal & Krt2 & 0.52 \\
A0A0G2JTP6_RAT & Perilipin & Plin1 Plin rCG_24621 & 0.56 \\
A0A0G2K0T6_RAT & Gamma-synuclein & Sncg rCG_42336 & 0.56 \\
A0A0H2UHF8_RAT & Alpha-1-acid glycoprotein & Orm1 & 0.57 \\
A0A0G2K586_RAT & Fatty acid-binding protein, adipocyte & Fabp4 & 0.57 \\
D3ZJ08_RAT & Histone H3 & rCG_51970 & 0.57 \\
B2RZ77_RAT & Dermatopontin & rCG_46203 & 0.58 \\
PGS2_RAT & Decorin & Dcn & 0.59 \\
Q5XIH1_RAT & Asporin & rCG_43984 & 0.60 \\
F7EUK4_RAT & Protein Kng2 & Kng111 Kng1 Kng2 & 0.60 \\
D3ZVB7_RAT & Osteoglycin & rCG_44112 & 0.62 \\
& & & \\
A0A0G2JST3_RAT & Keratin, type II cytoskeletal 1 & Krt1 & 0.62 \\
LUM_RAT & Lumican & LumLcnLdc & 0.62 \\
AL1A7_RAT & Aldehyde dehydrogenase, cytosolic1 & Aldh1a7 & 0.63 \\
F1LTN6_RAT & Protein Igkc & Igkc & 0.64 \\
K1C10_RAT & Keratin, type I cytoskeletal 10 & Krt10 Ka10 & 0.64 \\
D3ZJF8_RAT & Protein Fcgbp & Fcgbp & 0.64 \\
PRELP_RAT & Prolargin & Prelp & 0.65 \\
\hline
\end{tabular}


Table 3. Differentially expressed lncRNAs

\begin{tabular}{|c|c|c|c|c|c|}
\hline Probe name & Fold change & Regulatio & Probe name & Fold change & Regulation \\
\hline CUST_3277_PI428311958 & 9.57 & up & CUST_458_PI428311958 & 19.62 & down \\
\hline CUST_2772_PI428311958 & 9.08 & up & CUST_5519_PI428311958 & 18.85 & down \\
\hline CUST_8089_PI428311958 & 8.65 & up & CUST_2111_PI428311958 & 17.15 & down \\
\hline CUST_9208_PI428311958 & 8.54 & up & CUST_9135_PI428311958 & 15.42 & down \\
\hline CUST_2117_PI428311958 & 8.12 & up & CUST_8347_PI428311958 & 14.33 & down \\
\hline CUST_1197_PI428311958 & 8.02 & up & CUST_2931_PI428311958 & 13.49 & down \\
\hline CUST_384_PI428311958 & 7.94 & up & CUST_6638_PI428311958 & 12.14 & down \\
\hline CUST_7285_PI428311958 & 7.76 & up & CUST_4899_PI428311958 & 12.02 & down \\
\hline CUST_545_PI428311958 & 7.31 & up & CUST_396_PI428311958 & 11.75 & down \\
\hline CUST_4267_PI428311958 & 7.12 & up & CUST_8936_PI428311958 & 11.45 & down \\
\hline CUST__414__PI428311958 & 6.88 & up & CUST_6993_PPI428311958 & 11.18 & down \\
\hline CUST_8075_PI428311958 & 6.80 & up & CUST_8371_PI428311958 & 10.60 & down \\
\hline CUST_7733_PI428311958 & 6.65 & up & CUST_8040_PI428311958 & 9.37 & down \\
\hline CUST_6167_PI428311958 & 6.53 & up & CUST_887_PI428311958 & 9.36 & down \\
\hline CUST_4331_PI428311958 & 6.41 & up & CUST_4772_PI428311958 & 8.47 & down \\
\hline CUST_3632_PI428311958 & 6.37 & up & CUST_2963_PI428311958 & 8.16 & down \\
\hline CUST_9613_PI428311958 & 6.13 & up & CUST_2786_PI428311958 & 7.87 & down \\
\hline CUST_8256_PI428311958 & 6.05 & up & CUST_8955_PI428311958 & 7.68 & down \\
\hline CUST_8886_PI428311958 & 5.70 & up & CUST_7631_PI428311958 & 7.57 & down \\
\hline CUST__683__P1428311958 & 5.44 & up & CUST__878_PI428311958 & 7.22 & down \\
\hline
\end{tabular}

keratinocyte differentiation, immune response, cell cycle, platelet activation, and beta-alanine metabolism (Fig. 5).

\section{Interactions between Differentially}

Expressed Proteins

We established a protein-protein interaction (PPI) network based on 13 possible target-related proteins of reproduction and metabolism. Ingenuity pathway analysis (IPA) (http://www.
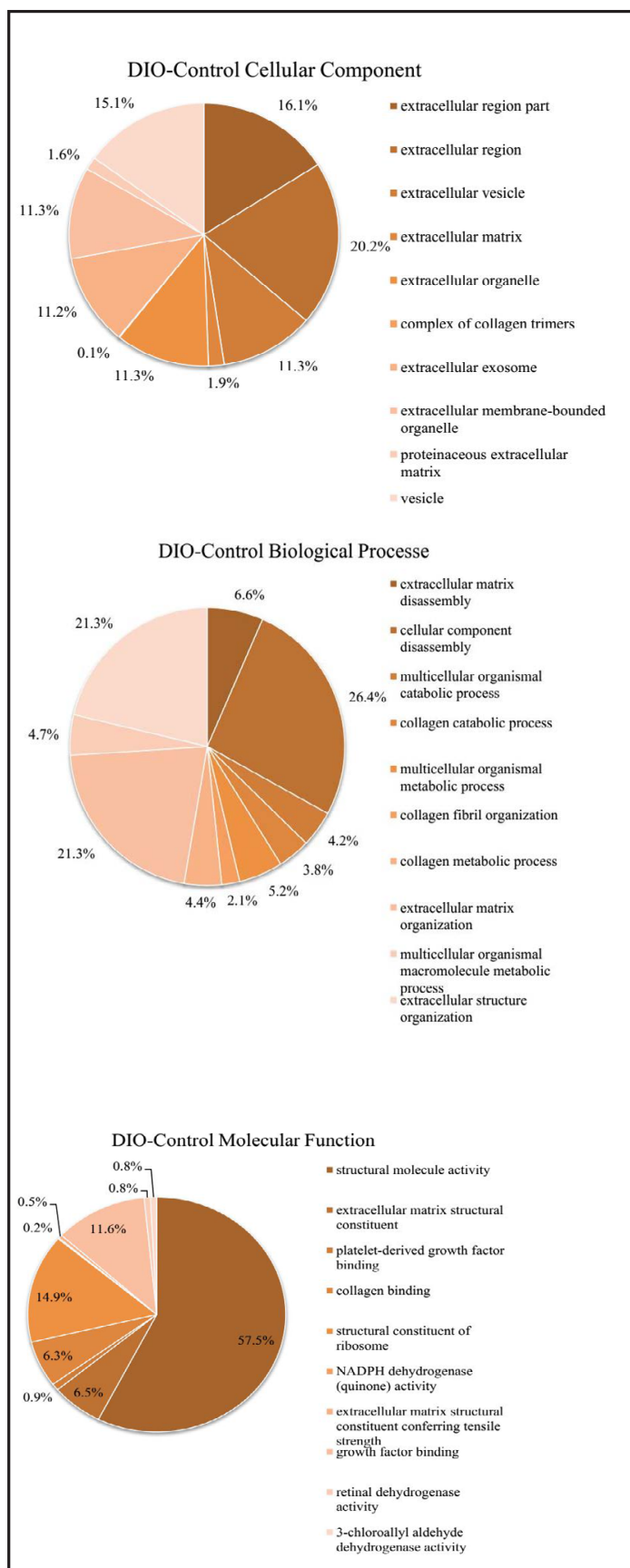

Fig. 4. Gene ontology enrichment for protein targets from testis samples. Gene ontology analysis of proteintarget genes according to cellular component, biological process, and molecular function. ingenuity.com) identifies protein networks from known interactions (either direct or indirect) between proteins. In addition, IPA defines common functional and canonical pathways, thereby offering additional information about the complex interactive lines between these proteins. The network comprises 35 proteins (Lcn5, PLCL2, SELENOS, PER3, LHCGR, CYP17A1, PLIN1, PLIN4, PTGR2, Ncoa6, FABP, MEDAG, PPARG, FABP4, RETSAT, ESR2, EPHA5, Spink2, S100A8, BRD8, BCL2, BANF1, HIST1H1D, MANBA, IL4, SMARCE1, MYC, CSTF1, APOA4, HIST1H1T, CARM1, SERINC3, 
Crisp1/Crisp3, CPOX, and FARP1), among which 13 proteins were quantified by iTRAQ. The remaining 22 proteins interact with the quantified proteins according to IPA (Fig. 6).

Co-expression analysis between IncRNAs and proteins

The metabolic GO and pathways involved in the differential metabolites were analyzed using the Metabo Analyst 2.0 software (http:// www.metaboanalyst.ca). As a result, we identified seven GO terms and two metabolic pathways found in both IncRNA and protein results associated with high-fat diet-induced male metabolic changes. These were characterized as single-organism catabolic process, protein complex subunit organization, cellular component organization, growth factor binding, oxidoreductase activity, extracellular matrix component, extracellular space, $\beta$-alanine metabolism, and retinol metabolism (Tables 4 and 5).

\section{Western blotting results}

We used western blot techniques to validate five differentially expressed proteins (Crisp1, Mapk1, Smad2, Epha5 and GAPDH).Antibodies against Smad2, Crisp1, Mapk1 and Epha5 were used to validate the differentially expressed proteins in the testis of male rat between the DIO and control groups. The iTRAQ analysis of protein expression for Smad2, Epha5, and Mapk1 was upregulated 1.59-, 2.17-, and 1.33fold, respectively, whereas Crisp1 was downregulated 0.76- fold compared with the normal group. Western blotting results showed that the expression level of Crisp1 considerably decreased, but the expression levels of Mapk1, Smad2, and Epha5 increased in the high-fat diet group compared with those in normal group (Fig.s 7A-7B). This result was consistent with the protein expression levels obtained using the iTRAQ approach.

\section{Discussion}

Obesity is a high risk factor for insulin resistance, type 2 diabetes, high-fat diet vascular diseases, endocrine disorders, and decreased fertility [11]. Studies show that lncRNA is 
Table 4. Overlap between protein and IncRNA GO analysis

\begin{tabular}{|c|c|c|c|c|}
\hline Name & $\begin{array}{l}\mathrm{p} \text {-value } \\
\text { (protein) }\end{array}$ & $\begin{array}{c}\text { Count } \\
\text { (protein) }\end{array}$ & $\begin{array}{c}\text { p-value } \\
\text { (IncRNA) }\end{array}$ & $\begin{array}{c}\text { Count } \\
\text { (IncRNA) }\end{array}$ \\
\hline $\begin{array}{l}\text { Single-organism } \\
\text { catabolic process }\end{array}$ & $3.729 \mathrm{E}-12$ & 26 & $5.05 \mathrm{E}-06$ & 148 \\
\hline $\begin{array}{c}\text { Protein complex } \\
\text { subunit organization }\end{array}$ & $2.315 \mathrm{E}-10$ & 31 & $4.36 \mathrm{E}-09$ & 305 \\
\hline $\begin{array}{l}\text { Cellular component } \\
\text { organization }\end{array}$ & $1.377 \mathrm{E}-07$ & 53 & $5.36 \mathrm{E}-06$ & 213 \\
\hline Growth factor binding & $3.165 \mathrm{E}-02$ & 5 & $1.35 \mathrm{E}-07$ & 33 \\
\hline $\begin{array}{l}\text { Oxidoreductase } \\
\text { activity }\end{array}$ & $7.071 \mathrm{E}-02$ & 11 & $1.44 \mathrm{E}-05$ & 133 \\
\hline $\begin{array}{l}\text { Extracellular matrix } \\
\text { component }\end{array}$ & 7.675E-11 & 11 & $3.68 \mathrm{E}-07$ & 34 \\
\hline Extracellular space & $6.356 \mathrm{E}-12$ & 29 & $8.16 \mathrm{E}-20$ & 247 \\
\hline
\end{tabular}

Table 5. Overlap between protein and IncRNA pathway analysis

\begin{tabular}{ccccc}
\hline Name & $\begin{array}{c}\text { p-value } \\
\text { (protein) }\end{array}$ & $\begin{array}{c}\text { Count } \\
\text { (protein) }\end{array}$ & $\begin{array}{c}\text { p-value } \\
\text { (IncRNA) }\end{array}$ & $\begin{array}{c}\text { Count } \\
\text { (IncRNA) }\end{array}$ \\
\hline Retinol metabolism & $2.521 \mathrm{E}-02$ & 72 & 0.4685499 & 10 \\
$\begin{array}{c}\text { Beta-alanine } \\
\text { metabolism/ }\end{array}$ & $5.005 \mathrm{E}-03$ & 31 & 0.0826913 & 7 \\
Rodent version & & & & \\
\hline
\end{tabular}

associated with obese male fertility [10]. The incidence of infertility in obese males is significantly higher than that in normal males [13]. Obesity and male infertility are closely related. Increased BMI has a negative impact on the levels of luteinizing hormone, testosterone, gonadotropin, sex hormone binding protein, and estradiol in men $[14,15]$.

In our study, 107 differentially expressed proteins were identified in the high-fat diet group. Among them, we focused on those proteins that have anti-oxidative functions and play a role in spermatogenesis. We also confirmed that lncRNAs were differentially expressed in testis samples from DIO and normal rats.

Among the 13 proteins in the protein network we established and quantified by iTRAQ, we identified Spink2 (serine protease inhibitor Kazal-type 2) gene, which belongs to the Spink family of proteins characterized by the presence of a Kazal-type serine protease inhibitor-pancreatic secretory trypsin inhibitor domain. Previous studies indicate that Spink family members are expressed in diverse tissues. However, only Spink2 is expressed in testes. Thus, it is considered essential for spermatogenesis [16, 17]. Moreover, Spink2 is necessary to inactivate acrosin during its transit through the endoplasmic reticulum and the Golgi apparatus. In the absence of Spink2, the Golgi apparatus is disorganized, preventing the production of the acrosome and inducing a block at the round spermatid stage [18]. Interestingly, we found the Spink2 gene was significantly upregulated in the rat testis with DIO, in contrast to previous reports. Because the sperm concentration and motility percentage in the high-fat diet group decreased, we speculate that Spink2 acts as a regulator to maintain the quantity of spermatozoa and normal spermatogenesis.

In mammals, Crisp1 is the first described member of the evolutionarily conserved Cysteine-Rich Secretory Protein (Crisp) family. It is a sperm protein expressed in the proximal regions of the epididymis, associates with sperm during maturation, and participates in 
fertilization [19-22]. It may have an effect on male reproduction through the TGF- $\beta$-mediated signaling pathway. Our results showed that Crisp1 was significantly downregulated.

From the protein network we established, we found 13 differentially expressed proteins forming a complex network related to reproduction. It is necessary to perform further studies to reveal the underlying mechanisms. Hist $1 \mathrm{~h} 1 \mathrm{t}$ forms less compacted chromatin compared to other $\mathrm{H} 1$ histone subtypes. Formation of more relaxed chromatin may be required to promote chromatin architecture required for proper chromosome regulation during meiosis [23]. We hypothesize the protein regulates the formation of sperm cells by influencing the synthesis of RNA. Lcn5 associates with spermatozoa in the epididymal fluid. It may act as retinoid carrier protein required for epididymal function or sperm maturation [24]. We also found that retinol metabolism components were altered at both IncRNA and protein levels. We speculate that obesity may affect the expression pattern of lncRNAs, further regulate the expression level of target proteins, and eventually lead to decreased spermatozoa during maturation.

Our pathway analysis revealed that the biological processes associated with differential expression of high-fat diet-induced obese rat testicular proteins include cytoskeleton remodeling, keratinocyte differentiation, immune response, cell cycle, platelet activation, and beta-alanine metabolism. Cytoskeleton remodeling may be associated with dysplasia whereas platelet activation may be due to decreased testicular tissue ischemia and oxygen levels $[25,26]$. Obesity-related alanine metabolic disorders may have an impact on the sperm membrane structure integrity and destroy oxidation resistance, which is a major factor in the decline of sperm fertility capacity $[27,28]$. $\beta$-alanine is the only limiting amino group for the synthesis of imidazole dipeptide acid and is a potential functional amino acid. $\beta$-alanine has a variety of physiological functions: regulating neurotransmitters and hormones, regulating body metabolism, serving as intermediate metabolites for variety of active substances (Coenzyme A, pantothenic acid, etc.), combating fatigue, and improving athletic ability. Due to variety of physiological functions, $\beta$-alanine has attracted a wide range of studies $[29,30]$. In this study, we found the $\beta$-alanine metabolism pathway not only regulated by proteins, but also by lncRNAs. According to this phenomenon, $\beta$-alanine metabolism may play an important role in male reproduction of obese rats induced by high-fat diet. The exact mechanism remains to be further explored.

In summary, we detected the differential expression of proteins and lncRNAs in the samples from high-fat diet rats and analyzed their potential roles through bioinformatics. The GO term enrichment analysis showed that the function most highly enriched was related to negative regulation of reproductive processes. Pathway analysis showed that metabolic pathways might be related to the high-fat diet-induced decline in male fertility. We also found some GO terms and metabolic pathways upregulated or downregulated in both protein and IncRNA analyses. Our results provide a foundation for future studies to investigate the molecular role of proteins and lncRNAs in high-fat diet associated decreases in male fertility.

\section{Abbreviations}

LncRNAs (long non-coding RNAs); GO (Gene Ontology); iTRAQ (isobaric tags for relative and absolute quantification); DIO (diet-induced obesity);

\section{Acknowledgements}

The National Nature Science Foundation of China (60601056); The National Natural Science Foundation of China (81774171); The International Cooperation Projects of MOE (2011DFA30920); Humanities and Social Sciences General Project, Ministry of Education of P.R. China (16YJCZH134). 


\section{Cellular Physiology Cell Physiol Biochem 2018;47:378-389

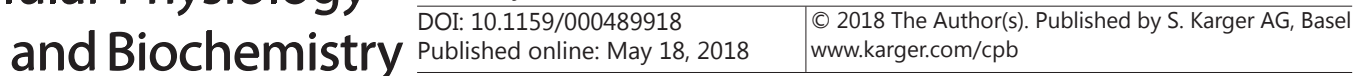 Jiang et al.: Effects of Obesity on Male Fertility}

Disclosure Statement

No potential conflicts of interest relevant to this article were reported.

\section{References}

1 Bakos HW, Mitchell M, Setchell BP, Lane M: The effect of paternal diet induced obesity on sperm function and fertilization in a mouse model. Int J Androl 2011;34:402-410.

$>2$ Moraes JC, Coope A, Morari J, Cintra DE, Roman EA, Pauli JR, Romanatto T, Carvalheira JB, Oliveira AL, Saad MJ, Velloso LA: High-fat diet induces apoptosis of hypothalamic neurons. PloS One 2009;4:e5045.

-3 Buffone MG, Verstraeten SV, Calamera JC, Doncel GF: High cholesterol content and decreased membrane fluidity in human spermatozoa are associated with protein tyrosine phosphorylation and functional deficiencies. J Androl 2009;30:552-558.

4 Bhat GK, Sea TL, Olatinwo MO, Simorangkir D, Ford GD, Mann DR: Influence of a leptin deficiency on testicular morphology, germ cell apoptosis, and expression levels of apoptosis-related genes in the mouse. J Androl 2006;27:302-310.

5 Malcher A, Rozwadowska N, Stokowy T, Jedrzejczak P, Zietkowiak W, Kurprisz M: The gene expression analysis of paracrine/autocrine factors in patients with spermatogenetic failure compared with normal spermatogenesis. Am J Reprod Immunol 2013;70:522-528.

6 Martini AC, Molina RI, Ruiz RD, Fiol de Cuneo M: Obesity and male fertility. Rev Fac Cien Med Univ Nac Cordoba 2012;69:102-110.

7 Mao Y, Xiong L, Li L: Comparison of the proteomes of mouse skin derived precursors (SKPs) and SKPderived fibroblasts (SFBs) by iTRAQ. J Cell Biochem 2018;119:1134-1140.

8 Hu J, Gao Z, Wang X, Gu M, Liang Y, Liu X, Hu S, Liu H, Liu W, Chen S, Peng D, Liu X: iTRAQ-based quantitative proteomics reveals important host factors involved in the high pathogenicity of the H5N1 avian influenza virus in mice. Med Microbiol Immunol 2017;206:125-147.

-9 Dou C, Cao Z, Yang B, Ding N, Hou T, Luo F, Kang F, Li J, Yang X, Jiang H, Xiang J, Quan H, Xu J, Dong S: Changing expression profiles of lncRNAs, mRNAs, circRNAs and miRNAa during osteoclastogenesis. Sci Rep DOI: $10.1038 /$ srep21499.

10 An T, Zhang T, Teng F, Zuo JC, Pan YY, Liu YF, Miao JN, Gu YJ, Yu N, Zhao DD, Mo FF, Gao SH, Jiang G: Long non-coding RNAs could act as vectors for paternal heredity of high fat diet-induced obesity. Oncotarget 2017;8:47876-47889.

11 Chen MM, Lan XX, Li CY, Tian ZM, Chen KF: Diet-induced obesity increases the apoptosis of testicular spermatogenic cells in pubertal male rats. Zhonghua Nan Ke Xue 2011;17:342-347.

12 Bradford MM: A rapid and sensitive method for quantitation of microgram quantities of protein utilizing the principle of protein-dye binding. Anal Biochem 1976;72:248-254.

13 Sermondade N, Faure C, Fezeu L, Shayeb AG, Bonde JP, Jensen TK, Van Wely M, Cao J, Martini AC, Eskandar M, Chavarro JE, Koloszar S, Twigt JM, Ramlau-Hansen CH, Borges E Jr, Lotti F, Steegers-Theunissen RP, Zorn B, Polotsky AJ, La Vignera S, Eskenazi B, Tremellen K, Magnusdottir EV, Fejes I, Hercberg S, Lévy $\mathrm{R}$, Czernichow S: BMI in relation to sperm count: an update dsystematic review and collaborative metaanalysis. Hum Reprod Update 2013;19:221-231.

-14 Hart RJ, Doherty DA, Mclachlan RI, Walls ML, Keelan JA, Dickinson JE, Skakkebaek NE, Norman RJ, Handelsman DJ: Testicular function in a birth cohort of young men. Hum Reprod2015;30:2713-2724.

15 Fui MN, Dupuis P, Grossmann M: Lowered testosterone in male obesity: mechanisms, morbidity and management. Asian J Androl 2014;16:223-231.

16 Erdemir F, Atilgan D, Markoc F, Boztepe O, Suha-Parlaktas B, Sahin S: The effect of diet induced obesity on testicular tissue and serum oxidative stress parameters. Actas Urol Esp 2012;36:153-159.

17 Kherraf ZE, Christou-Kent M, Karaouzne T, Amiri - Yekta A, Martinez G, Vargas AS, Lambert E, Borel C, Dorphin B, Aknin - Seifer I, Mitchell MJ Metzler-Guillemain C, Escoffier J, Nef S, Grepillat M, Thierry-Mieg N, Satre V, Bailly M, Boitrelle F, Pernet-Gallay K, Hennebicq S, Fauré J, Bottari SP, Coutton C, Ray PF, Arnoult C: Spink2 deficiency causes infertility by inducing sperm defects in heterozygotes and azoospermia in homozygotes. EMBO Mol Med 2017;9:1132-1149. 


\section{Cellular Physiology Cell Physiol Biochem 2018;47:378-389

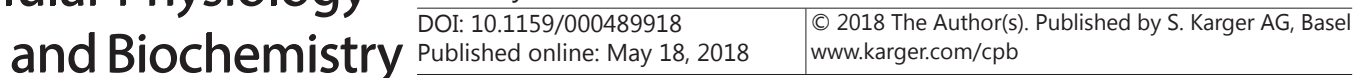 \\ Jiang et al.: Effects of Obesity on Male Fertility}

18 Lee B, Park I, Jin S, Choi H, Kwon JT, Kim J, Jeong J, Cho BN, Eddy EM, Cho C: Impaired spermatogenesis and fertility in mice carrying a mutation in the Spink2 gene expressed predominantly in testes. J Biol Chem 2011;286:29108-29117.

19 Chen T, Lee TR, Liang WG, Chang WS, Lyu PC: Identification of trypsin-inhibitory site and structure determination of human Spink2 serine proteinase inhibitor. Proteins 2009;77:209-219.

-20 Cohen DJ, Maldera JA, Vasen G, Ernesto JI, Muñoz MW, Battistone MA, Cuasnicú PS: Epididymal protein CRISP1 plays different roles during the fertilization process. J Androl 2011;32:672-678.

-21 Roberts KP, Ensrud-Bowlin KM, Piehl LB, Parent KR, Bernhardt ML, Hamilton DW: Association of the protein D and protein D and protein E forms of rat CRISP1 with epididymal sperm. Biol Reprod 2008;79:1046-1053.

-22 Da Ros VG, Maldera JA, Willis WD, Cohen DJ, Goulding EH, Gelman DM, Rubinstein M, Eddy EM, Cuasnicu PS: Impaired sperm fertilizing ability in mice lacking cysteine-rich secretory protein 1 (CRISP1). Dev Biol 2008;320:12-18.

23 El Kennani S, Adrait A, Shaytan AK, Khochbin S, Bruley C, Panchenko AR, Landsman D, Pflieger D, Govin J: MS_Histone DB, a manually curated resource for proteomic analysis of human and mouse histones. Epigenetics Chromatin DOI: 10.1186/s13072-016-0109-X.

24 Xie S, Xu J, Ma W, Liu Q, Han J, Yao G, Huang X, Zhang Y: Lcn5 promoter directs the region-specific expression of cre recombinase in caput epididymidis of transgenic mice. Biol Reprod DOI: 10.1095/ biolreprod.112.104034.

25 Zhao M, Liu J, Li Y, Jiang Y: Regulatory mechanisms of ERK signal transduction pathway. Int J Path and Clin Med 2009;29:15-19.

-26 Woo SM, Kim J, Han HW, Chae JI, Son MY, Cho S, Chung HM, Han YM, Kang YK: Notch signaling is required for maintaining stem-cell features of neuroprogenitor cells derived from human embryonic stem cells. BMC Neurosci DOI: 10.1186/1471-2202-10-97.

-27 Simonson TS, Yang Y, Huff CD, Yun H, Qin G, Witherspoon DJ, Bai Z, Lorenzo FR, Xing J, Jorde LB, Prchal JT Ge R: Genetic evidence for high-altitude adaptation in Tibet. Science 2010;329:72-75.

28 Tena-Sempere M, Barreiro ML: Leptin in male reproduction: the testis paradigm. Mol Cell Endocrinol 2002;188: 9-13.

29 Kralik G, Sak Bosnar M, Kralik Z, Galović O: Effects of $\beta$-alanine dietary supplementation on concentration of carnosine and quality of broiler muscle tissue. J Poul Sci 2014;51:151-156.

-30 Everaert I, Stegen S, Vanheel B, Taes Y, Derave W: Effect of beta-alanine and carnosine supplementation on muscle contractility in mice. Med Sci Sports Exerc 2013;45:43-51. 